Article

\title{
Optimization of the National Land Space Based on the Coordination of Urban-Agricultural-Ecological Functions in the Karst Areas of Southwest China
}

\author{
Xiaoqing Zhao ${ }^{1, *}, \operatorname{Sinan~}_{\mathrm{Li}^{1}}{ }^{1} \mathbb{D}$, Junwei Pu ${ }^{2} \mathbb{C}$, Peipei Miao ${ }^{1}$, Qian Wang ${ }^{1}$ and Kun Tan ${ }^{1}$ \\ 1 School of Resource Environment and Earth Science, Yunnan University, Kunming 650500, China; \\ lsn0705@163.com (S.L.); mp1029907902@gmail.com (P.M.); wangqian.ynu@foxmail.com (Q.W.); \\ tankun666@mail.ynu.edu.cn (K.T.) \\ 2 Institute of International Rivers and Eco-Security, Yunnan University, Kunming 650500, China; \\ pujunwei666@foxmail.com \\ * Correspondence: xqzhao@ynu.edu.cn; Tel.: +86-138-8894-9695
}

Received: 28 October 2019; Accepted: 25 November 2019; Published: 28 November 2019

\begin{abstract}
National land spatial planning is dominated by urban-agricultural-ecological functions and has become a Chinese national strategic issue. However, the three functional spaces have serious conflicts in the karst areas, causing inconsistencies in regional development and triggering poverty and a more serious situation for the ecological environment. In this study, we used the gray multi-objective dynamic programming model and the conversion of land use and its effects at small region extent model to simulate the developmental structures of future land use in the karst areas of Southwest China under a socioeconomic development scenario, an arable land protection scenario and an ecological security scenario. Finally, based on the coordination of the urban-agricultural-ecological functions, we used a functional space classification method to optimize the spatial structures of the national land space for 2035 year and to identify different functional areas. The results showed that the three scenarios with different objectives had differences in the quantities and spatial structures of land use but that the area of forestland was the largest and the area of water was the smallest in each scenario. The optimization of the national land space was divided into seven functional areas-urban space, agricultural space, ecological space, urban-agricultural space, urban-ecological space, agricultural-ecological space and urban-agricultural-ecological space. The ecological space was the largest and the urban-ecological space was the smallest among seven functional areas. The different types of functional spaces had significant differentiation characteristics in the layouts. The urban-agricultural space, urban-ecological space, agricultural-ecological space and urban-agricultural-ecological space can effectively alleviate the impacts of human activities and agricultural production activities in karst areas, promote the improvement of rocky desertification and improve the quality of the regional ecological environment. The results of this research can provide support for decisions about the balanced development of the national land space and the improvement of environmental quality in the karst areas.
\end{abstract}

Keywords: national land spatial planning; urban-agricultural-ecological functions; coordinated development; GMDP-CLUE-S coupling model; karst areas; southwest China

\section{Introduction}

With the continuous expansion of urban and rural construction land, the space for agricultural and ecological land uses is condensed and the conflict among urban space, agricultural space and ecological space is intensified. The different scales have an uncoordinated contradiction between people and nature, production and life, especially within the natural system. Given the background of 
new urbanization and urban and rural development, there are many problems such as the chaotic order of national land space development and the heavy resource and environmental costs in the rapid economic growth and social transformation. And those problems have always been a major scientific proposition in the field of regional sustainable development [1]. Rocky desertification in karst areas is one of the three major ecological disasters in China. The worsening problem of rocky desertification seriously threatens the safety of the ecological environment, restricts socioeconomic development and has a serious impact on people's productivity and lives [2,3]. Chinese karst areas are mainly distributed in the southwestern region. This region is one of the three largest concentrated karst distribution areas in the world and has the largest exposed carbonate area and the strongest karst development [4,5] and it is also an important recharge area for the water sources of the Pearl River and Yangtze River in China and has an important ecological barrier function [6]. Severe rocky desertification threatens regional ecological security and restricts sustainable socioeconomic development. In recent years, a large number of ecological restoration projects have been implemented in the karst areas of Southwest China [7-9]. The regional status of rocky desertification and the ecological environment has improved but the quality of the ecological environment is still under tremendous pressure [10-13]; in addition, the ecological vulnerability is still high [14-16]. The land use patterns have a strong impact on the rocky desertification status. With changes in land use structures, rocky desertification has also undergone tremendous changes [17-19]. Therefore, the adjustment of the land use structures can promote the improvement of rocky desertification status and the sustainable development of regional ecological environments.

Previous studies of national land space primarily have had two main focuses. One focus was land multifunctional perspective, exploring the relationship between land use and versatility [20,21]. At the same time, there was a study that analyzed the relationship between land versatility and sustainable development [22]. Another focus was the regulation of regional land use structures from the relationship between the land and the internal environment of the natural system. The focal point was on spatial planning from multiple perspectives, such as ecosystem value [23] and climate change [24].

Thereafter, some studies have carried out the partitioning and optimization of the national land space for the main functional areas and carried out many exploration in the aspects of the partition framework, indicator systems and zoning technology [25]. Based on the suitability of regional functions [25,26] and the resource and environment carrying capacity [27], methods of optimizing the spatial patterns in the national land space are constantly appearing. Some studies have also analyzed the functional characteristics of the national land space in terms of niche theory [28-30] and suitability theory [31] and they have classified and optimized the national land space based on land functions [32-35]. However, in current regional development, the coordination of urban space, agricultural space and ecological space are seriously neglected, which causes conflicts among the three functional spaces and affects the stability of the spatial structures. For these reasons, China proposed national spatial planning that was dominated by urban-agricultural-ecological functions. The emphasis of the planning is on accurately determining the development direction of regional land and rationally optimizing that development. The plan has also become one of the Chinese national strategies.

In summary, previous studies have been devoted to exploring the division among land use functions and the synergistic development relationship between land functions and the surrounding environment. However, they have rarely paid attention to the coordinated development of land functions and socioeconomic-ecological status and the coordination degree and carrying capacity of the water and land resources have not been considered comprehensively. At the same time, they have paid little attention to the collaborative development of the urban-agricultural-ecological functions. At present, there is still a lack of comprehensive research on the optimization of the national land space under the coordination of the urban-agricultural-ecological functions. In addition, the study of the national land space in karst areas with severe spatial conflicts has received limited attention. Therefore, 
it is a great theoretical and practical significance to study the optimization of national land space in karst areas from the aspect of the coordination of urban-agricultural-ecological functions.

In this study, the land use data and socioeconomic data from 2000, 2010 and 2018 were taken into consideration. We comprehensively considered the regional water-land resources coupling coordination degree, the resource and environment carrying capacity. From the perspectives of society, economy and ecology, the GMDP-CLUE-S coupling model, a model that combined GMDP model and CLUE-S model [36], was used to optimize the land use quantities and spatial structures in 2035 year under a socioeconomic development scenario, an arable land protection scenario and an ecological security scenario. We also superimposed the results of the division of the dominant land use functions, which divided the three scenarios with the functional space classification method and corrected the overlay results by ecological priority correction rules to obtain the results of the optimization of national land space based on the coordination of urban-agricultural-ecological functions in Guangnan County, which is a typical karst region in Southwest China. The objectives of the study were as follows-(1) based on the water and land resources coupling coordination degree and the resource and environment carrying capacity, simulate the development structures of future land use under the three scenarios of socioeconomic development, arable land protection and ecological security in karst areas; (2) identify and analyze the types and functions of urban-agricultural-ecological functions with the coordination of national land space; (3) explore the role of the research results in the control of rocky desertification and provide reference for the future planning of national land space in karst areas.

\section{Materials and Methods}

\subsection{Study Area}

Guangnan County $\left(104^{\circ} 31^{\prime}-105^{\circ} 39^{\prime} \mathrm{E}, 23^{\circ} 29^{\prime}-24^{\circ} 28^{\prime} \mathrm{N}\right)$, a typical mountainous county with karst rocky desertification, in Yunnan Province, Southwest China $(\mathrm{d} 1)$. The county is located on the slope of the Yunnan-Guizhou Plateau and extends to Eastern Guizhou; it is a part of the karst plateau in Southeast Yunnan and is a hilly area of the mountain plateau. The terrain is sloped from a higher altitude in the southwest to lower altitude in the northeast. The county covers an area of $7730.09 \mathrm{~km}^{2}$ with 94.7\% mountainous and semi-mountainous areas and ranks third in size in Yunnan Province. Guangnan County belongs to the Yunnan-Guangxi-Guizhou karst rocky desertification areas. The karst landforms are distributed widely, accounting for three-quarters of the total area of the county and exhibit serious rocky desertification. It also has a frontier minority area dominated by agriculture. It has a poor economy, low productivity, frequent geological disasters and a very fragile natural ecological environment. In addition, the methods of resource development and utilization are unreasonable, the ecological environment is seriously damaged and the environmental problems are prominent (see Figure 1). 


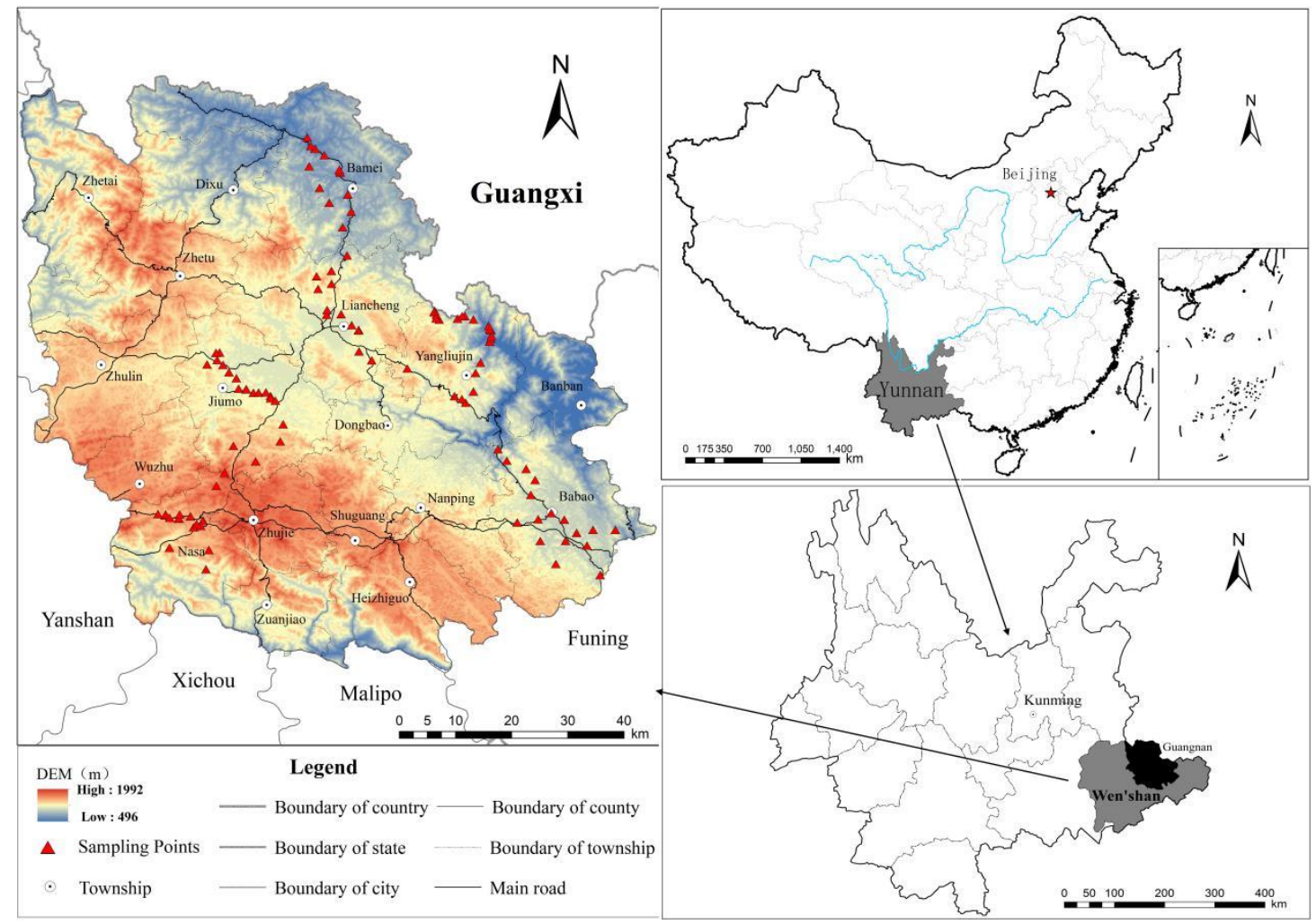

Figure 1. The location of Guangnan County in Yunnan Province of Southwest China.

\subsection{Data Acquisition and Study Process}

This study used Landsat 5 TM data with 30m spatial resolution for 2000 and 2010 and Landsat 8 TM data with $15 \mathrm{~m}$ spatial resolution for 2018. All remote sensing images were free that were collected from http://www.gscloud.cn/ and corrected with atmospheric and geometric correction. According to the spectral characteristics, texture features and shapes of the images, nine land types (paddy field, dry land, garden, forestland, grassland, urban construction land, rural settlement, waters and unutilized land) and five rocky desertification types (no rocky desertification, potential rocky desertification, mild rocky desertification, moderate rocky desertification and severe rocky desertification) were extracted and classified with both manual- and computer-based methods by ENVI version 5.1 and ArcGis version 10.1. We performed field work in the study area and collected 126 sample points of land use types and 141 sample points of rocky desertification types (all points were mainly involving the land types that were difficult to distinguish and that changed considerably). The accuracies were calculated to be $90.45 \%$ and $85.11 \%$ through the comparison of the collected samples and the classified results. The results of the interpretation met the research needs.

In addition, the Land Use General Plan (2016-2030), Geological Disaster Prevention Plan (2011-2020), Soil and Water Conservation Plan (2017-2026), Statistical Yearbook, precipitation data, topographic data, soil physical and chemical properties data were collected from the Land Resources Bureau, Meteorological Bureau, Statistical Bureau of Guangnan County. All of those data were collected from the government department of the study area and could not be found in any website. And we obtained the consent of the government department to use those data in this study.

Based on the above data, the research steps are shown in Figure 2. 


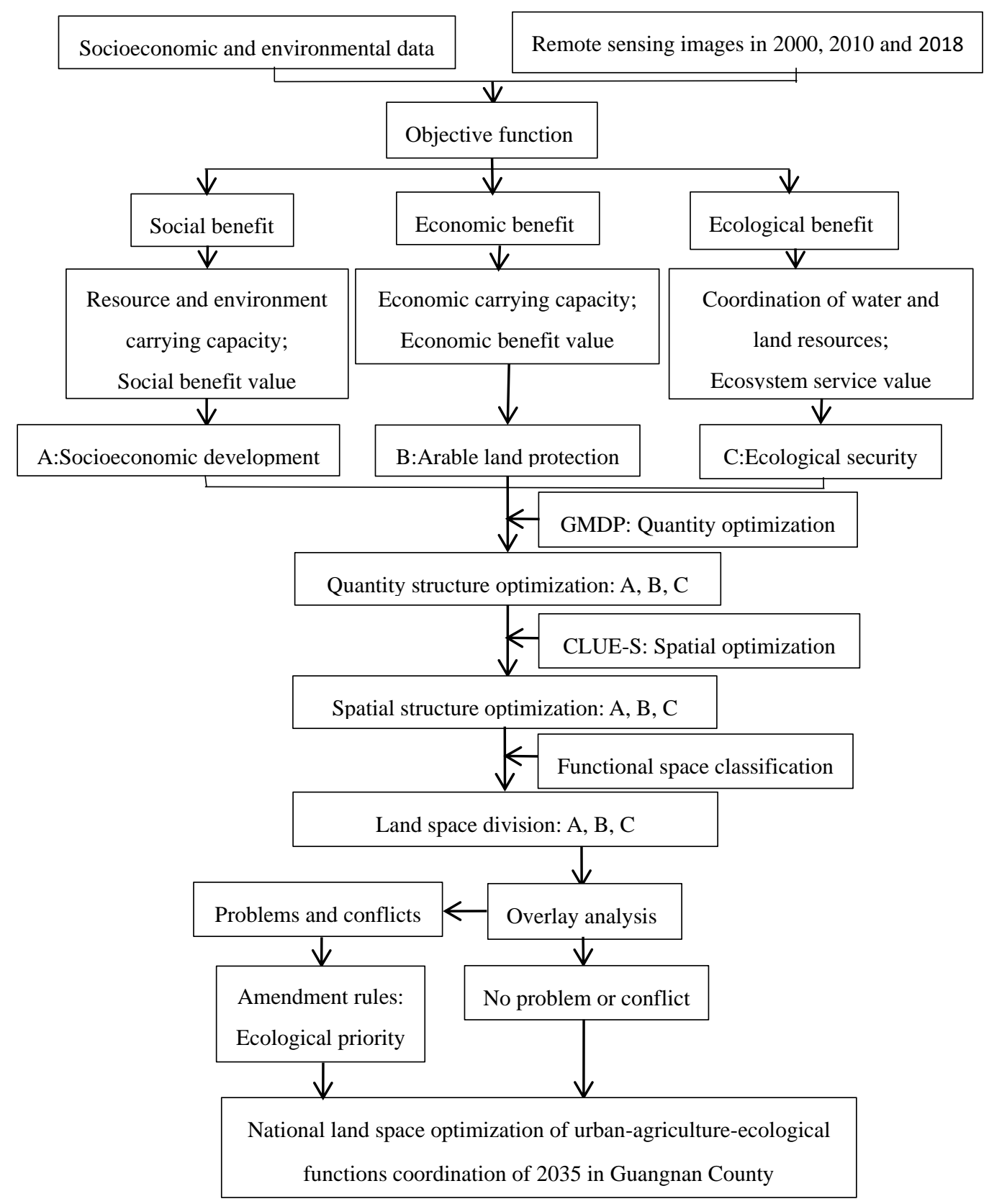

Figure 2. Technical roadmap.

\subsection{Optimization of the Land Use Quantity Structures Based on the GMDP Model}

A gray multi-objective dynamic programming (GMDP) model is an optimization system that derives from the intersection of multi-objective linear programming and gray prediction theory. The main idea is to define the uncertain objective functions and constraints in a satisfactory range with a certain scope [37]. Based on the land use data and socioeconomic data in 2000, 2010 and 2018, we used a MATLAB model to predict the research data (e.g., population data, economic data, agricultural data). Then, the study debugged the objective functions and constraints by using LINGO software [38] multiple times and compared the optimization results to obtain optimization programs of the land use quantities and structures for 2035. According to the future development strategy and the goal orientation of the study area, we categorized these optimization programs into three scenarios-the socioeconomic development scenario, the arable land protection scenario and the ecological security scenario. 


\subsubsection{Objective Functions Setting}

Under the premise of the comprehensive consideration of the water and land resources coupling coordination degree, the resource and environment carrying capacity, the ecological environment and the socioeconomic development in karst areas, we chose three aspects (i.e., society, economy and ecology) as the benefit goals of the optimization of land use quantity structures and we constructed multi-objective functions that were suitable for the optimization of the quantities and structures of land use in karst areas. The social benefit goal comprehensively considered the social benefit value and the resource and environment carrying capacity, the economic benefit goal comprehensively considered the value of the economic benefits and the economic carrying capacity and the ecological benefit goal comprehensively considered the water and land resources coupling coordination degree and the value of ecosystem services. At the same time, we calculated six objective functions of the study area and superimposed those functions with 9 land use types by using ArcGis. The average value of each objective function of each land use type was obtained and was used as the parameter of the objective function. Each objective function is as follows (among which $x_{1}, x_{2}, x_{3}, x_{4}, x_{5}, x_{6}, x_{7}, x_{8}$, and $x_{9}$ represent paddy fields, dry land, garden, forestland, grassland, urban construction land, rural settlement, waters and unutilized land, respectively.):

(1) Social benefit goal:

$$
\begin{gathered}
\max F_{1}(x)=\frac{0.166\left(6\left(x_{1}+x_{2}\right)+0.207 x_{3}+0.173\left(x_{4}+x_{5}\right)+0.326\left(x_{6}+x_{7}\right)+0.128 x_{8}\right.}{P} \\
\max _{2}(x)=3.145 x_{1}+2.799 x_{2}+2.799 x_{2}+3.314 x_{3}+2.791 x_{4}+2.681 x_{5}+3.543 x_{6}+3.349 x_{7} \\
+3.145 x_{8}+2.523 x_{9}
\end{gathered}
$$

where $F_{1}(x)$ represents the value of the social benefit of land use; $F_{2}(x)$ represents the of the resource and environment carrying capacity; and $P$ represents the total population of 2035.

(2) Economic benefit goal:

$$
\begin{gathered}
\max _{3}(x)=1329.84\left(x_{1}+x_{2}\right)+502.38 x_{3}+177.31 x_{4}+886.56 x_{5}+6279.80\left(x_{6}+x_{7}\right)+59.10 x_{8}+x_{9} \\
\max _{4}(x)=2.7852 x_{1}+2.7926 x_{2}+2.6368 x_{3}+2.5093 x_{4}+2.5994 x_{5}+2.4617 x_{6}+2.8283 x_{7} \\
+2.7382 x_{8}+2.4158 x_{9}
\end{gathered}
$$

where $F_{3}(x)$ represents the value of the economic benefit of land use and $F_{4}(x)$ represents the economic carrying capacity.

(3) Ecological benefit goal:

$$
\begin{gathered}
\max F_{5}(x)=0.5062 x_{1}+0.5061 x_{2}+0.5047 x_{3}+0.5094 x_{4}+0.5017 x_{5}+0.4858 x_{6}+0.4926 x_{7} \\
+0.5093 x_{8}+0.5062 x_{9} \\
\max F_{6}(x)=12714.20\left(x_{1}+x_{2}\right)+37152.80 x_{3}+45248.96 x_{4}+18785.79 x_{5}-8637.60\left(x_{6}+x_{7}\right) \\
+72985.79 x_{8}+3804.73 x_{9}
\end{gathered}
$$

$F_{5}(x)$ represents the water and land resources coupling coordination degree; and $F_{6}(x)$ represents the ecosystem services value.

\subsubsection{Setting the Constraint Conditions}

According to the demographic data of the study area from 2000-2018, we used the GM(1,1) gray system model and the growth rate trend model to predict the population of the study area and we calculated the gray range of the total population of the study area to be [920736,941981] for 2035. Because the urbanization rate was expected to reach $48.33 \%$ by 2030 , the gray range of the urban 
population was [444992,455259] and the gray range of the rural population was [475744,486722]. The portion of the population was involved in the constraint equation was calculated by the gray range.

To carry out the regional land use overall plan and water resource protection plan to protect arable land, promote urban and rural scientific development, improve the ecological environment and safeguard water resources and based on the relevant literature [39-41] and field work, we selected a total area constraint, arable land constraint, garden constraint, forestland constraint, grassland constraint, urban construction land constraint, rural settlement constraint, waters constraint, unutilized land constraint, water supply constraint and mathematical model constraint to be constraint conditions for 21 constraint equations.

\subsection{Optimization of the Spatial Structure of Land Use Based on the CLUE-S Model}

Based on the results of the land use quantity optimization in the three scenarios, we used the CLUE-S model to optimize the spatial structures of the land in the study area under the three scenarios.

The CLUE-S model was divided into two parts-a nonspatial module (land use demand) and a spatial module (land use change and distribution) [42,43]. In this study, the result of land use quantity optimization in 2035 was used as the land use demands of the nonspatial module. The spatial module was used to determine the influence factors of the distribution of the nine types of land use and a binary logistic regression model was used to analyze the distribution patterns of the influence factors and to conduct a spatial layout simulation by continuous iteration [44]. The formula of the binary logistic regression model is as follows:

$$
\log \frac{P_{i}}{1-P_{i}}=\beta_{0}+\beta_{1} X_{1, i}+\beta_{2} X_{2, i} \ldots \beta_{n} X_{n, i}
$$

where $p_{i}$ represents the probability of land use type $i$ in each grid; $\beta_{0}$ is a constant term; $\beta_{1}, \cdots, \beta_{n}$ represents the correlation between the driving factors of $X_{1, j}, \cdots, X_{n, j}$ and land use type $i$; $X$ represents driving factor types.

\subsubsection{Research Scale}

In the binary logistic regression analysis, the driving factors of the different scales have different beta coefficients for each land use type $[45,46]$. On the basis of the comprehensive consideration of the spatial resolution of remote sensing images and the scale requirements of the CLUE-S models, we converted the 9 types of land use and the driving factors of various types into five different scales (i.e., $100 \mathrm{~m} \times 100 \mathrm{~m}, 200 \mathrm{~m} \times 200 \mathrm{~m}, 300 \mathrm{~m} \times 300 \mathrm{~m}, 600 \mathrm{~m} \times 600 \mathrm{~m}$ and $800 \mathrm{~m} \times 800 \mathrm{~m}$ ) and we also used the ROC values to compare the results by using 2018 as an example to select $20 \%$ of samples for a binary logistic regression analysis. The results showed that the simulation was most effective when the grid cell was $200 \mathrm{~m} \times 200 \mathrm{~m}$, so $200 \mathrm{~m} \times 200 \mathrm{~m}$ was selected as the research scale.

\subsubsection{Probability Simulation of Land Use Suitability}

\section{(1) Driving factor selection}

According to studies on the driving factors of land use change [47-50] and the characteristics of land use change in karst areas, based on the selection of the evaluation indicators of the karst areas in the Main Functional Area Planning of Yunnan Province and the related planning, we selected nineteen indicators such as land use structures, soil erosion, vegetation coverage rate and rock bareness rate from the aspects of the ecological driving factors, natural driving factors, socioeconomic driving factors, arable land driving factors, water resource driving factors and location driving factors as driving factors of land use change in the karst areas. 
(2) Binary logistic regression analysis

We inputted the nine land use types and nineteen land use driving factors into the SPSS version 22 for the binary logistic regression analysis and finally obtained the space suitability probability for each land use type. The accuracy of the spatial suitability probability was tested by a relative operating characteristic (ROC) curve [42]. The selected factors were classified as having a good interpretation ability when the ROC value is larger than 0.7 [42]. The results showed that the ROC values of the paddy fields, dry land, garden, forestland, grassland, urban construction land, rural settlement, waters and unutilized land were $0.746,0.705,0.767,0.773,0.745,0.817,0.802,0.876$ and 0.718 , respectively. All ROC values were greater than 0.7 , which indicated that the fitting effect of each land use type was very good.

\subsubsection{CLUE-S Model Input Settings}

(1) Space policies and regional restrictions

The spatial policies and regional restrictions refer to the regions where the functions of land could not be changed. In this study, the basic farmland areas, the ecological protection areas that were denoted by red lines, the important water source areas, the moderate rocky desertification areas and the severe rocky desertification areas were set as the regions that could not be converted.

(2) Land use transfer rules

The land use transfer rules were divided into two parts-the elastic coefficient of land use transfer and the land use transfer matrix [42].

At present, there is no precise calculation method for the elastic coefficient of land use transfer. Based on the relevant literature and research results [43-46], this study combined the land use transfer rule and the stability of the land itself in 2000, 2010 and 2018. We first set the elastic coefficients of land use transfer for various types of land use, then compared the simulation results in 2018 with the actual land use distribution and finally we determined the final elastic coefficients of various types of land use by multiple adjustments. The elastic coefficients of the paddy fields, dry land, garden, forestland, grassland, urban construction land, rural settlement, waters and unutilized land were $0.8,0.78,0.82$, $0.8,0.8,0.9,0.9,0.95$ and 0.68 , respectively.

The land use transfer matrix represents the possibility of the mutual transformation between the land use types [42]. The land use transfer matrix was set by analyzing the changes in land use types in 2000, 2010 and 2018 and combining with the status of the land use and the positions of the main regional functions. In this study, nine types of land use could be transformed into each other.

(3) Land use demands

In this study, the land use demands of the CLUE-S model were set by the optimization results of the land use quantity structure in 2035 under three scenarios based on the GMDP model.

(4) Accuracy testing of the simulation results

The status of the land use distribution in 2000 was used as the starting data and the current status of land use distribution in 2018 was used as the demand data for the forecast period. We used the simulation map in 2018 and the current map in 2018 to perform the Kappa index test. The final result showed that the Kappa value was 0.856 , which indicated that the simulation of the spatial distribution of land use in 2018 was very good.

\subsection{Optimization of National Land Space Based on Urban-Agricultural-Ecological Functions Coordination}

In the Chinese National Spatial Planning Outline (2016-2030) of 2017, the national land space is divided into three categories (i.e., urban space, agricultural space and ecological space). Each type of land use may show versatility but the difference in the ways, intensities and targets of the land use 
could cause the land to show the primary and secondary functions of urban function, agricultural function and ecological function (i.e., the main functions of land use) $[21,33,34]$.

According to the land use status and the functional status of the various land use types in the karst areas, we established a spatial classification system of urban-agricultural-ecological functions based on the classification of the land use status in the study area and obtained the dominant functions of the identified land uses in karst areas (Table 1).

In the process of regional development, a land type can simultaneously combine urban, agricultural and ecological functions. Therefore, to achieve the internal coordination of the urban spaces, agricultural spaces and ecological spaces, we reclassified the land use optimization of 2035 under the three scenarios according to Table 1 and we also used ArcGis version 10.1 to superimpose the reclassification results. For the superposition results, we aimed to improve the ecological environment of the karst areas and amended them based on the following amendment rules:

(1) priority was given to ensuring the area of ecological space in the karst areas and the ecological function land areas and ecological protection areas that were denoted by red lines in the optimization results were allocated to ecological space; (2) second, this study ensured the stability of the agricultural spatial structure, the urban space with heavy fragmentation in the plane areas and the permanent basic farmland areas were allocated to agricultural space; (3) according to the scope of the delineation of the urban expansion boundaries for the relevant planning of the study area, the scale of urban space was appropriately adjusted with a goal of preserving land and intensifying use; and (4) the areas where the two or three functions were suitable in the superposition results were classified into multifunctional areas with multiple functional clusters.

Table 1. Identification table of the dominant functions of the land uses.

\begin{tabular}{cccc}
\hline Classification & Land Use Type & Land Function Type & Dominant Function Type \\
\hline 1 & Paddy field & Agriculture-ecology & Agriculture \\
2 & Dry land & Agriculture-ecology & Agriculture \\
3 & Garden & Agriculture-ecology & Agriculture \\
4 & Forestland & Agriculture-ecology & Ecology \\
5 & Grassland & Ecology-agriculture & Ecology \\
6 & Urban construction land & Urban & Urban \\
7 & Rural settlement & Agriculture-urban & Agriculture \\
8 & Waters & Ecology-agriculture & Ecology \\
9 & Unutilized land & Ecology-agriculture & Ecology \\
\hline
\end{tabular}

\section{Results}

\subsection{Optimization of the Land Use Quantity Structures}

Because the three scenarios have different optimization objectives, there are also large gaps in the structures of the quantities of various types of land use. Table 2 shows the structures of the land use quantities under the three scenarios.

(1) Under the socioeconomic development scenario, the area of urban construction land and the area of rural settlement reached the maximum demand of the population during the forecast period of 2035, which were 52.35 and $63.27 \mathrm{~km}^{2}$. The area of the garden, forestland, waters and unutilized land was increasing, with values of $670.84,4321,32.15$ and $1118.36 \mathrm{~km}^{2}$, respectively. The area of other land use types was decreasing;

(2) Under the arable land protection scenario, the area of arable land showed an overall growth trend that was $11.07 \%$ higher than that of 2018. The area of paddy field decreased and the area of dry land increased by 184.2 and $1504.28 \mathrm{~km}^{2}$, respectively. The area of the garden, forestland, waters and unutilized land increased by $10.54,311.14$ and $24.08 \mathrm{~km}^{2}$, respectively and the remaining five land use types were decreasing. 
(3) Under the ecological security scenario, the largest increase in the areas were those in forestland and waters, which were 4893.78 and $49.38 \mathrm{~km}^{2}$, respectively. The area of the garden increased to $373.96 \mathrm{~km}^{2}$ and other land use types were decreasing.

Table 2. Optimization of the land use quantities in different scenarios (Measure Unit: $\mathrm{km}^{2}$ ).

\begin{tabular}{|c|c|c|c|c|c|}
\hline \multirow[b]{2}{*}{ Classification } & \multirow{2}{*}{$\begin{array}{l}\text { Land Use } \\
\text { Types }\end{array}$} & \multicolumn{3}{|c|}{ Scenario Modes } & \multirow{2}{*}{$\begin{array}{l}\text { Current } \\
\text { Situation }\end{array}$} \\
\hline & & $\begin{array}{c}\text { Socioeconomic } \\
\text { Development }\end{array}$ & $\begin{array}{l}\text { Arable Land } \\
\text { Protection }\end{array}$ & $\begin{array}{c}\text { Ecological } \\
\text { Security }\end{array}$ & \\
\hline 1 & Paddy field & 295.52 & 184.20 & 196.04 & 387.19 \\
\hline 2 & Dry land & 1034.88 & 1504.28 & 983.4 & 1133.03 \\
\hline 3 & Garden & 670.84 & 373.96 & 373.96 & 363.45 \\
\hline 4 & Forestland & 4321.00 & 4424.80 & 4893.78 & 4113.66 \\
\hline 5 & $\begin{array}{c}\text { Grassland } \\
\text { Urban }\end{array}$ & 141.72 & 231.56 & 141.72 & 569.75 \\
\hline 6 & $\begin{array}{c}\text { construction } \\
\text { land }\end{array}$ & 52.35 & 51.17 & 51.17 & 58.72 \\
\hline 7 & $\begin{array}{c}\text { Rural } \\
\text { settlement }\end{array}$ & 63.27 & 61.85 & 61.85 & 94.16 \\
\hline 8 & Waters & 32.15 & 49.38 & 49.38 & 25.29 \\
\hline 9 & Unutilized land & 1118.36 & 848.89 & 978.79 & 984.84 \\
\hline
\end{tabular}

\subsection{Optimization of the Spatial Structures of Land Use}

The optimization results of the spatial structures in the three scenarios were very different (Figure 3).

The socioeconomic development scenario aimed to achieve the maximum socioeconomic benefit and to obtain the highest resource and environment carrying capacity for human activities. In this scenario, the guaranteed construction land area was the most important and food demand and security were the main criteria for arable land but the minimum demands for production, human lives and the environment were the baseline for the area of forestland, grassland and waters. The emphasis of the scenario was on the development of construction land and economic growth, which had a large burden on the regional land resources. As shown in Figure 3a, under this scenario, the urban construction land and rural settlements in the study area tended toward intensive use and the reduction of the spatial scale was more obvious. The urban construction land was mainly distributed in the middle and northwest of the study area and the rural settlement was the mixed distribution with arable land. The garden regions expanded outwards and were mainly distributed in the north and south of the study area, along with the small regions in the northwest. The other land use types were increased or decreased but their changes were not obvious.

The arable land protection scenario aimed to effectively protect arable land resources. A system of balancing the occupation and compensation of arable land in the protection strategy was strictly implemented to ensure the stability and safety of the arable land space. As shown in Figure $3 b$, under this scenario, the pressure on arable land was still relatively large in the future, the available land that could be developed and cultivated as arable land was limited and the degeneration rate of the paddy field was still very fast. Much dry land was sorted and merged from the regions which were urban construction land with unreasonable use, rural settlement with high fragmentation, grassland and unutilized land with low degrees of rocky desertification under land abandonment of natural and human factors. The growth of forestland and the reduction of unutilized land were more significant. The former was mainly located in the north and northwest of the study area, which was converted from garden; the latter was mainly distributed in the rocky desertification areas in the south of the study area, which were mainly converted to dry land. Among other land use types, the urban construction land and rural settlement tended to maintain their lands and have intensive use and their distribution ranges were narrowed, while the waters were increased and grassland was reduced. 
The ecological security scenario focused on protecting ecological land (e.g., forestland, grassland, waters) and it increased the area of ecological land to promote the construction of a regional ecologically friendly civilization through a series of ecological restoration projects, such as returning farmland to forestland and controlling rocky desertification for ecological security. As shown in Figure 3c, under this scenario, the spatial extent of the forestland in the study area grew rapidly. The implementation of ecological restoration projects converted too much land into forestland. These land use types mainly included garden, which was in the northwest and southeast; urban construction land and rural settlements with high degrees of fragmentation; arable land, which is far from the areas of human activities; grassland; and unutilized land, which was in the potential and mild rocky desertification areas. As the demand for water resources was increased, the area of waters also expanded. However, the range of unutilized land had a growing trend in moderate and severe rocky desertification regions and the ecological pressure in these regions was still enormous.

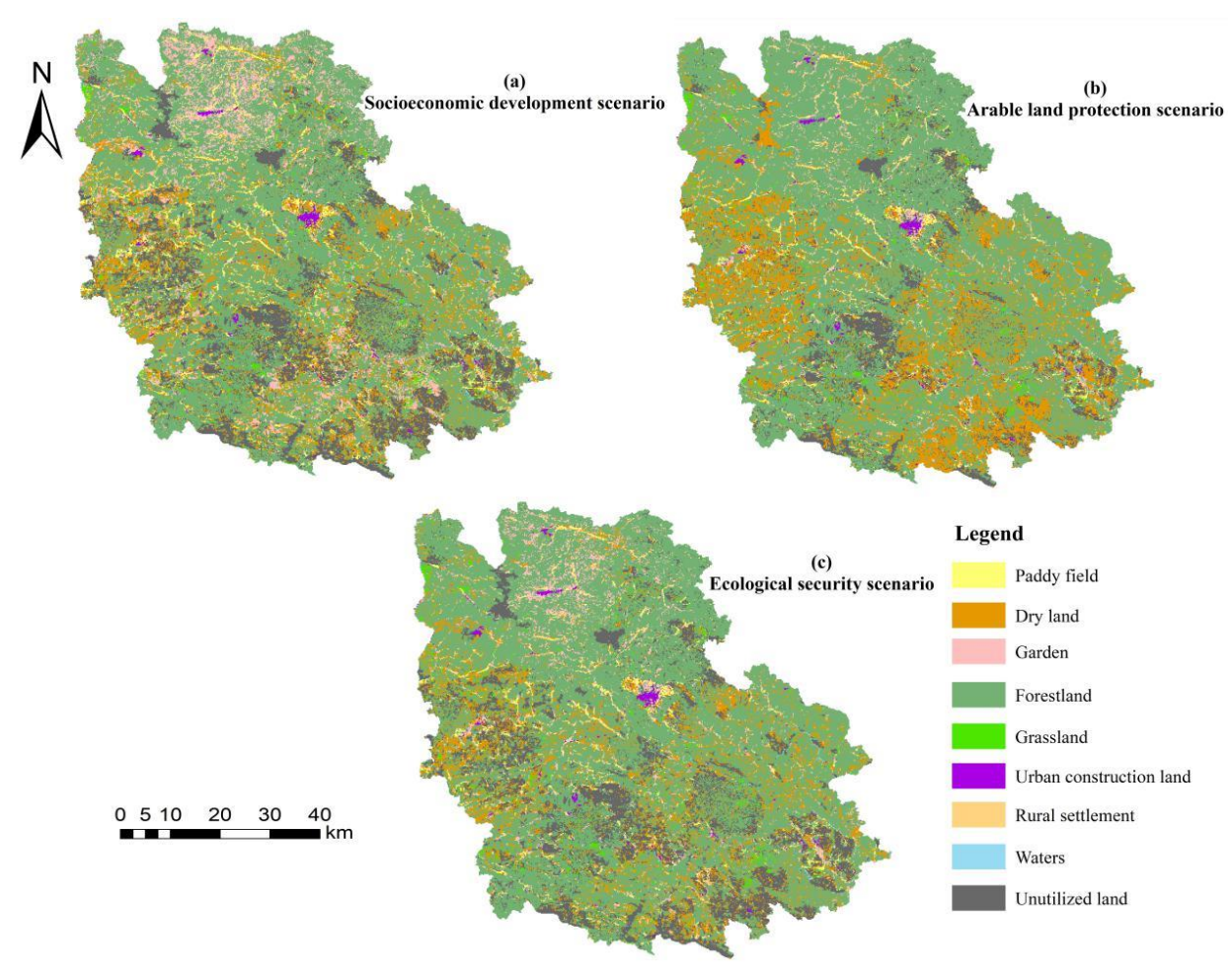

Figure 3. Optimization of the spatial structure of land use in 2035 under different scenarios-(a) Socioeconomic development scenario; (b) Arable land protection scenario; (c) Ecological security scenario.

\subsection{Optimization of the National Land Space Based on the Urban-Agricultural-Ecological Functions Coordination}

The national land space was divided into seven spatial types (i.e., urban space, agricultural space, ecological space, urban-agricultural space, urban-ecological space, agricultural-ecological space and urban-agricultural-ecological space) and their areas were 40.35, 1315.51, 5186.32, 24.25, 5.44, 1141.53 and $16.69 \mathrm{~km}^{2}$, respectively.

(1) Urban space-The urban space was mainly distributed in the center and northwest of the study area, with a small number of areas in the southwest and northwest (Figure 4). From the perspective of the optimization results, it tended to highly intensive use, which was mainly located in the plane areas with high quality geological environments and high quality natural environments. The urban space in the moderate and severe rocky desertification regions with poor living environments was entirely relocated. The optimized distribution of the urban space not only improved the daily living conditions of the residents but also reduced the pressure of the human activities on the severe rocky desertification 
areas. It also provided good conditions for the improvement of the ecological environment and the implementation of ecological management projects in the severe rocky desertification areas.

(2) Agricultural space-The agricultural space was widely distributed throughout the study area and the highest concentration was in the west and south (Figure 4). From the perspective of the optimization results, the scope of the agricultural spatial layout has expanded that compared with the current situation of agricultural space in 2018 and its expansion regions were mainly distributed in the potential and mild rocky desertification regions. Under ecological restoration projects, the agricultural space in the severe rocky desertification areas that had poor geological environments and poor farming environments had been comprehensively rectified and was converted into ecological space (e.g., forestland, grassland) dominated by ecological functions.

(3) Ecological space-The ecological space was the most widely distributed land use type in the whole territory. The area of the ecological space accounted for $67.09 \%$ of the study region and the highest concentrations of the land use type were located in the northwest, northeast and southwest (Figure 4). From the perspective of the optimization results, the distribution of regional ecological space was greatly improved in 2035. The dispersed urban space with poor living environments and the agricultural spaces with poor farming conditions were centrally rectified and divided into protected and managed ecological space. The division of ecological space had great significance for the improvement of the ecological environment in the study area and the improvement of the happiness of residents. However, within the ecological space, nearly $20 \%$ of the area exhibited severe rocky desertification. In the future development process, the centralized protection and remediation of the region should rely on its own ability to regenerate and the method of natural restoration should be the main strategy, while human management should be supplemental for improving the quality of the ecological environment in severe rocky desertification areas.

(4) Urban-agricultural space-The urban-agricultural space was mainly distributed around the urban space, which was largely in the middle of the study area; a small number of the urban-agricultural space was contained within the agricultural space in the west and south (Figure 4). From the perspective of the results of the optimization, the urban-agricultural space was mainly located at the intersection of urban and agricultural space. In the future development process, urban-agricultural spaces could not only serve as urban space to meet the demand for urban space because of regional population increases and socioeconomic development but could also serve as agricultural space to meet the needs of residents for food.

(5) Urban-ecological space-The urban-ecological space was mainly distributed in the southeast of the study area (Figure 4). From the perspective of the results of the optimization, it was mainly located around the Bamei Scenic Area in the study area and it was a combination of recreational areas and ecological protection areas. In the future development and planning process, it will not only be used as an ecological space to protect the ecological environment but also used as an urban development space that is suitable for ecological protection, such as a scenic spot. However, it should pay attention to the protection of the ecological environment in the process.

(6) Agricultural-ecological space-The agricultural-ecological space was mainly distributed in the north, south and west of the study area (Figure 4). From the perspective of optimization results, the agricultural-ecological space was mainly located in the current rocky desertification areas in 2018 , so this space type could provide a good environmental basis for the management of rocky desertification in the karst areas. In future development, the local government should focus on the protection of this area, while the cultivation of ecological-agricultural products can be carried out while maintaining ecological quality.

(7) Urban-agricultural-ecological space-The urban-agricultural-ecological space was mainly distributed in the northeast and southeast of the study area (Figure 4). This space type will have the most diverse land use functions in the process of regional development and it should be focused on the protection of ecological space and the establish of a good foundation for the control of rocky desertification and the protection of the ecological environment in karst areas. After the improvement 
of the regional rocky desertification status, the space can be used as urban construction space to increase the living area of residents and can also be used as agricultural space to increase the amount of arable land. Therefore, the supply of ecological space should be given priority in this space and then the scope of the urban space should be expanded and the efficiency of the agricultural space should be improved. Finally, the advantages of each group should be utilized to promote the coordinated development of regional national land space.

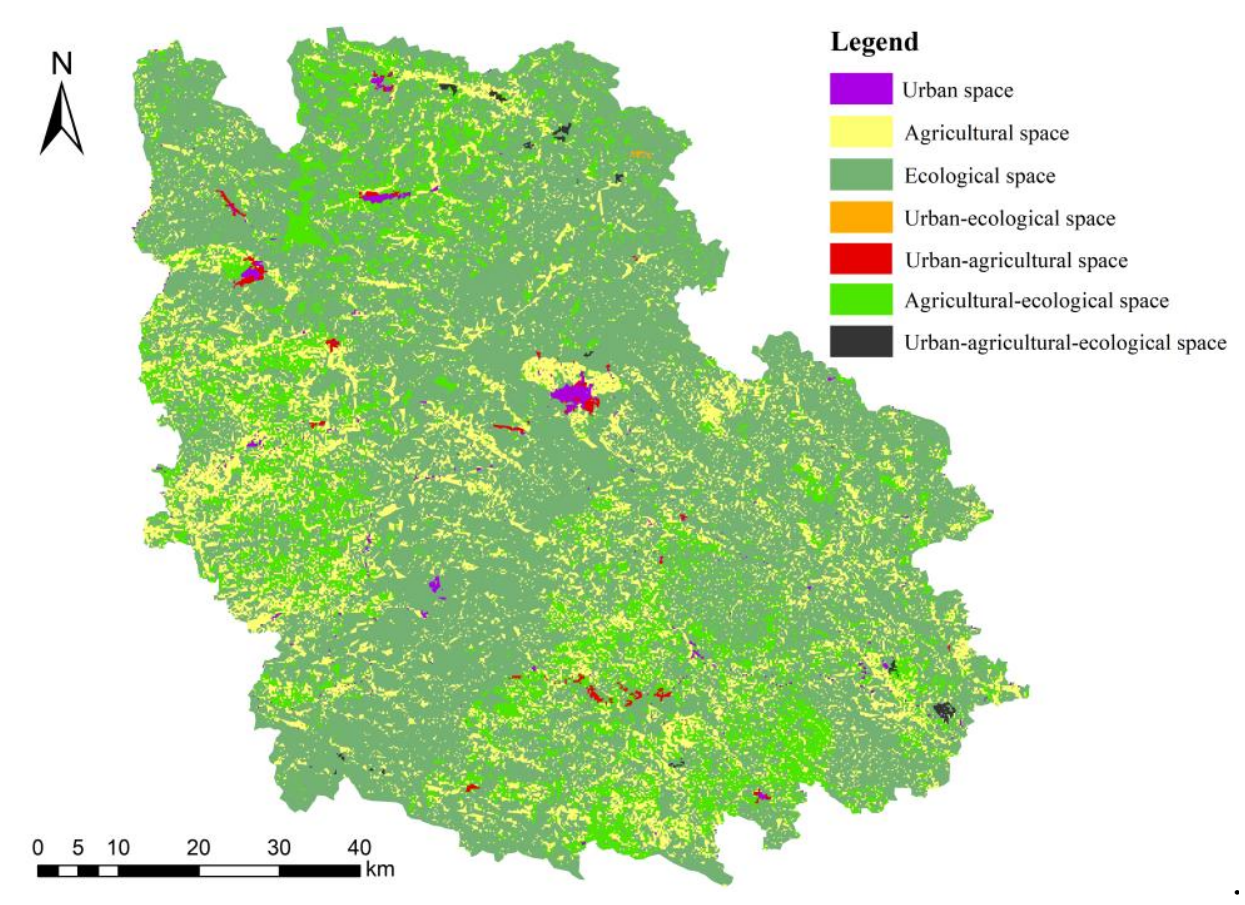

Figure 4. Optimization of the national land space based on the coordination of urban-agricultural-ecological functions.

\section{Discussion}

\subsection{Land Use Optimization Methods for Karst Areas}

In this study, the resource and environment carrying capacity and the water and land resources coupling coordination degree were taken as the objective functions for the optimization of the land use quantity and spatial structures in karst areas. The resource and environment carrying capacity can represent the development potentiality of the regional land space [51-54] and the water and land resources coupling coordination degree can represent the relevance and synergy of the changes in various elements within the water and land resources $[55,56]$. The combination of these factors can reflect the regional resource background and the development potential in the future, especially in karst areas. Previous studies on land use optimization have focused on optimizing the land use structures from the aspects of natural ecosystems [57-59], artificial ecosystems (e.g., urban and cropland systems) [60-63] and multi-factor coupling benefits [64-66]. However, most studies have not taken into account the regional resource background.

On the basis of the resource background, from the perspective of the regional ecological environment, resource environment and social environment, we proposed a method to optimize the land use structures in the karst areas by using the GMDP-CLUE-S coupling model. And then, we simulated the development structures of future land use under the three scenarios of socioeconomic development, arable land protection and ecological security. The land use structures of different scenarios were different (Figure 3) but each program fully considered the current conditions of resource and environment. These scenarios not only have great significance for the improvement of the rocky desertification status and the restoration of ecological environment but also can supplement and adjust 
the implementation of rocky desertification control projects in Chinese karst areas. In addition, we found that all karst areas had the same ecological environment and resource characteristics in the studies of different karst areas [67-71]. Therefore, the methods of land use optimization of this study have a strong applicability value for the global karst areas.

At the same time, projecting land use change is incredibly challenging and uncertain [72]. The uncertainty of many factors (e.g., environmental, incidental) may cause actual results to be inconsistent with predicted results $[73,74]$ and their uncertainty changes will make a huge change in the development trend of land use, so it is necessary to consider the uncertainty in the forecast. Our predicted results of land use change were based on the land use change law of the study area from 2000 to 2018 and the land use planning policies of the future and we fully considered the regional social, economic and environmental characteristics. The social benefit value, the resource and environment carrying capacity, the economic benefit value, the economic carrying capacity, the water and land resources coupling coordination degree and the ecosystem service value were set as the objective functions. Considering the above situations, the predicted results had high credibility. In the prediction of land use quantities, the fluctuation range of 9 types of land use was set by simulating 3 scenarios and the land use quantities were different because of different scenarios. The fluctuation values of forestland, dry land, garden, unutilized land, paddy fields, grassland, waters, rural settlement and urban construction land were sorted from large to small and they were 572.78, 520.88, 296.88, 267.47, $111.32,89.84,17.23,1.42$ and $1.18 \mathrm{~km}^{2}$, respectively. The average values of those land use types were $4546.53,1174.19,472.92,982.01,225.25,171.67,43.64,62.32$ and $51.56 \mathrm{~km}^{2}$, respectively. However, because of the uncertainty of a lot of factors in the future, those land use quantities cannot be seen as stone values but they can provide the reference for the development of regional land use.

\subsection{The Concept of the Coordinated Development of the Urban-Agricultural-Ecological Functions}

We comprehensively considered the current ecological environment of the karst areas [67-69] and the development of the regional national land space $[33,34]$ to propose the concept of coordinated development of urban-agricultural-ecological functions and explore a method to achieve the coordination. This study applied the concept and method to optimize the national land space in the karst areas. In recent years, in studies of optimization of national land space, researchers have not only explored the optimization of natural systems such as resource development and ecological environment [75-77] but also conducted many studies on the spatial optimization of the relationship between natural systems and social systems [78-80]. These studies have promoted the sustainable development of the regional national land space and provided a theoretical basis for the researches on coordinated development of other factors. However, in the current development patterns of Chinese national land space, the expansion of urban space has accelerated and the decrease of agricultural space and ecological space has become a key issue that hinders Chinese development. Coordinated studies of urban space, agricultural space and ecological space have become an important topic in the studies of regional development.

At the same time, to our knowledge, this is the first study to use the concept of the coordinated development of urban-agricultural-ecological functions to optimize the national land space in karst areas. In other studies of other areas, this concept has received limited attention [81]. The application of the concept can effectively alleviate the conflicts and contradictions between the three functional spaces within the regions, enable rational planning of the distributions of functional spaces and ably identify the multifunctional areas with multiple functional clusters to promote regional socioeconomic sustainable development. Especially in karst areas, the application of the concept can fundamentally improve the quality of the ecological environment, coordinate the structures of land use and promote the green development of the regions. 


\subsection{Feasibility Analysis of the Results of National Land Space Optimization}

In this study, we used a functional space classification method to divide the spatial structures of karst areas into seven spatial types (Figure 4) —urban space, agricultural space, ecological space, urban-agricultural space, urban-ecological space, agricultural-ecological space and urban-agricultural-ecological space. The land use structures can be composed of a single function or a combination of urban-agricultural-ecological functions; the types of national land space in the results can be explained by this principle [33]. In karst areas, because of the complexity of the resource and environment, determining and identifying different functional areas is not only an effective way to plan and manage the national land space [82] but also an important significance for the restoration of the ecological environment.

Our research results showed that the urban space was mainly distributed in the plane areas and the urban-agricultural space was widely distributed around the urban space. These spatial distribution patterns could effectively reduce the pressure of human activities on limited natural resources and provide a transition zone between urban space and agricultural space to prevent the occupation of agricultural space and restrict the soil and water pollution which is caused by the various pollutants of urban $[83,84]$. At the same time, the distribution of urban-ecological space can effectively alleviate the pressure of crowded living spaces.

Agricultural space has great significance for the protection of food security. However, human activities in agricultural space will magnify the situation of rocky desertification and non-point source pollution in the space will pose considerable threats to the sustainable use of land resources [85]. However, in Figure 4, we see that these threats are not without a solution. Agriculture-ecological space was widely distributed around the agricultural space. The existence of agriculture-ecological space established a natural barrier between agricultural space and ecological space, which isolated the interference of human activities on rocky desertification and limited the impact of agricultural pollution on the ecological environment.

Ecological space has the strongest influence on karst areas and its spatial distribution structures will change the repair rate of rocky desertification [86]. In this study, the urban space and agricultural space that were in the severe rocky desertification regions, were converted to ecological space. And these regions should control rocky desertification status and improve the quality of the ecological environment with the goal of "natural restoration and prevention of human interference." At the same time, the existence of urban-agricultural-ecological space provides a green space for land consolidation in the future development of karst areas.

In addition, the spatial types that were dominated by urban space and agricultural space were mainly distributed in the areas which had better ecological environment and higher resource and environment carrying capacity. At the same time, the range of urban space and agricultural space in severe and moderate desertification areas was reduced. These ways eased the impact of natural disasters on daily lives and agricultural industry, provided a good environment for people's life and production and increased people's productivity and lives. At the same time, by dividing three single functional spaces and four composite functional spaces, socioeconomic activities, agricultural industry development and ecological protection can be closely linked. Our results showed that different functional areas had different aggregation modes and development directions. In the areas with good ecological environment, economic construction and industrial development were focused to promote economic activities, management urban construction and improve people's quality of life under the premise of protecting ecological security. But green land was also preserved in this process to ensure the stability and development of ecological functions [87]. In the areas with poor ecological environment, urban space and agricultural space were transferred outwards on a large scale and the construction of green infrastructure and the movement of industrial structure were used as land sharing methods to improve local ecological structure [83]. 


\section{Conclusions}

In this study, based on the current status of the resource and environment in karst areas of Southwest China, we proposed three scenarios for the development structures of land use in the future-socioeconomic development, arable land protection and ecological security. The first scenario guaranteed that the demand for construction land would be met and various types of land tended to intensive use. The second scenario guaranteed arable land resources and alleviated ecological pressure. The third scenario aimed to protect the regional ecological land and build a natural barrier for the management of rocky desertification.

In addition, from the perspective of the coordination of urban-agricultural-ecological functions, we proposed a new optimized concept for the national land space in karst areas. In the optimized results, the structures of the national land space were divided into seven spatial types-urban space, agricultural space, ecological space, urban-agricultural space, urban-ecological space, agricultural-ecological space and urban-agricultural-ecological space. Their area was 40.35, 1315.51, 5186.32, 24.25, 5.44, 1141.53 and $16.69 \mathrm{~km}^{2}$, respectively. Each special type had different distribution pattern but all of them could supplement and adjust the implementation of rocky desertification control projects in the future. On the one hand, by transferring people's high-intensity activity areas and increasing the range of green space and ecological agriculture in karst areas, it improved the local ecological structure and planting methods and reduced the interference of natural disasters on economic activities and urban construction; on the other hand, through the rational arrangement of urban space and economic agricultural industry and the promotion of spatial types that were dominated by ecological space in the plain area, the people's living area and the economic industry were improved, urban construction, people's life, industrial development and ecological protection were organically combined to promote regional sustainable development. Their spatial results provide a valuable reference for the directions of national land spatial planning in the study area and other similar areas. The delineation of each space can provide a good foundation for the improvement of rocky desertification and the enhancement of the ecological environment in the karst areas of Southwest China. National spatial planning presents both opportunities and challenges towards a sustainable future for regional development.

Author Contributions: Conceptualization, X.Z. and S.L.; Methodology, X.Z. and S.L.; Software, S.L. and J.P.; Validation, P.M. and Q.W.; Formal analysis, X.Z. and K.T.; Investigation, S.L. and P.M.; Resources, X.Z. and J.P.; Data curation, Q.W. and K.T.; Writing-original draft, S.L., J.P. and P.M.; Writing-review \& editing, X.Z. and S.L.; Visualization, Q.W. and K.T.; Project administration, J.P. and Q.W.; Funding acquisition, X.Z.

Funding: This research was supported by the Joint Fund of Yunnan Provincial Science and Technology Department and Yunnan University [2018FY001(-017)]; National Natural Science Foundation of China [41361020]; Project of Innovative Talents Cultivation for Graduate Students of Yunnan University [C176230200]; and Project of First-class Discipline Construction of Yunnan University-Geography [C176210103; C176210215].

Acknowledgments: We thank the support given by the government in Guangnan County. All remote sensing images were obtained from http://www.gscloud.cn/. We are grateful to the reviewers and editors for their insightful and constructive comments.

Conflicts of Interest: The authors declare no conflict of interest.

\section{References}

1. Wang, X.; Zhao, X.L.; Zhang, Z.X.; Yi, L.; Zuo, L.J.; Wen, Q.K.; Liu, F.; Xu, J.; Hu, S.; Liu, B. Assessment of soil erosion change and its relationships with land use/cover change in China from the end of the 1980s to 2010. Catena 2016, 137, 256-268. [CrossRef]

2. Bai, X.Y.; Wang, S.J.; Xiong, K.N. Assessing spatial-temporal evolution processes of karst rocky desertification land: Indications for restoration strategies. Land Degrad. Dev. 2013, 24, 47-56. [CrossRef]

3. Chen, H.S.; Liu, J.W.; Wang, K.L.; Zhang, W. Spatial distribution of rock fragments on steep hillslopes in karst region of northwest Guangxi, China. Catena 2011, 84, 21-28. [CrossRef]

4. Yan, X.; Cai, Y.L. Multi-scale anthropogenic driving forces of karst rocky desertification in southwest China. Land Degrad. Dev. 2015, 26, 193-200. [CrossRef] 
5. Yan, Y.J.; Dai, Q.H.; Yuan, Y.F.; Peng, X.D.; Zhao, L.S.; Yang, J. Effects of rainfall intensity on runoff and sediment yields on bare slopes in a karst area, SW China. Geoderma 2018, 330, 30-40. [CrossRef]

6. Fu, Z.Y.; Chen, H.S.; Zhang, W.; Xu, Q.X.; Wang, S.; Wang, K.L. Subsurface flow in a soil-mantled subtropical dolomite karst slope: A field rainfall simulation study. Geomorphology 2015, 250, 1-14. [CrossRef]

7. Tong, X.W.; Wang, K.L.; Yue, Y.M.; Brandt, M.; Liu, B.; Zhang, C.; Liao, C.; Fensholt, R. Quantifying the effectiveness of ecological restoration projects on long-term vegetation dynamics in the karst regions of southwest China. Int. J. Appl. Earth Obs. Geoinf. 2017, 54, 105-113. [CrossRef]

8. Li, H.; Cai, Y.; Chen, R.; Chen, Q.; Yang, X. Effect assessment of the project of grain for green in the karst region in Southwestern China: A case study of Bijie Prefecture. Acta Ecol. Sin. 2011, 31, 3255-3264. (In Chinese)

9. Qi, X.K.; Wang, K.L.; Zhang, C.H. Effectiveness of ecological restoration projects in a karst region of southwest China assessed using vegetation succession mapping. Ecol. Eng. 2013, 54, 245-253. [CrossRef]

10. Fan, Z.M.; Li, J.; Yue, T.X.; Zhou, X.; Lan, A.J. Scenarios of land cover in Karst area of southwestern China. Enviorn. Earth Sci. 2015, 74, 6407-6420. [CrossRef]

11. Liu, Y.; Huang, X.J.; Yang, H.; Zhong, T.Y. Environmental effects of land-use/cover change caused by urbanization and policies in southwest China Karst area-a case study of Guiyang. Habitat. Int. 2014, 44, 339-348. [CrossRef]

12. Zhang, Z.; Chen, X.; Huang, Y.; Zhang, Y. Effect of catchment properties on runoff coefficient in a karst area of southwest China. Hydrol. Process. 2014, 28, 3691-3702. [CrossRef]

13. Yang, Q.Y.; Zhang, F.W.; Jiang, Z.C.; Yuan, D.X.; Jiang, Y.J. Assessment of water resource carrying capacity in karst area of Southwest China. Enviorn. Earth Sci. 2016, 75, 1-8. [CrossRef]

14. Guo, F.; Jiang, G.H.; Yuan, D.X.; Polk, J.S. Evolution of major environmental geological problems in karst areas of Southwestern China. Environ. Earth Sci. 2013, 69, 2427-2435. [CrossRef]

15. Yang, Q.Y.; Jiang, Z.C.; Yuan, D.X.; Ma, Z.L.; Xie, Y.Q. Temporal and spatial changes of karst rocky desertification in ecological reconstruction region of southwest China. Environ. Earth Sci. 2014, 72, 4483-4489. [CrossRef]

16. Xiao, K.; He, T.; Chen, H.; Peng, W.; Song, T.; Wang, K.; Lin, D. Impacts of vegetation restoration strategies on soil organic carbon and nitrogen dynamics in a karst area, southwest China. Ecol. Eng. 2017, 101, 247-254. [CrossRef]

17. Jiang, Y.J.; Li, L.L.; Groves, C.; Yuan, D.; Kambesis, P. Relationships between rocky desertification and spatial pattern of land use in typical karst area, Southwest China. Environ Earth Sci. 2009, 59, 881-890. [CrossRef]

18. Zhao, M.; Zeng, C.; Liu, Z.H.; Wang, S.J. Effect of different land use/land cover on karst hydrogeochemistry: A paired catchment study of Chenqi and Dengzhanhe, Puding, Guizhou, SW China. J. Hydrol. 2010, 388, 121-130. [CrossRef]

19. Xiao, H.L.; Weng, Q.H. The impact of land use and land cover changes on land surface temperature in a karst area of China. J. Environ. Manag. 2007, 85, 245-257. [CrossRef]

20. Verburg, P.H.; van de Steeg, J.; Veldkamp, A.; Willemen, L. From land cover change to land function dynamics: A major challenge to improve land characterization. J. Environ. Manag. 2009, 90, 1327-1335. [CrossRef]

21. Ren, M.Y.; Lin, Y.Y.; Jin, M.J.; Duan, Z.Y.; Gong, Y.X.; Liu, Y. Examining the effect of land-use function complementarity on intra-urban spatial interactions using metro smart card records. Transportation 2019, 4, $1-23$.

22. Galler, C.; Von, H.C.; Albert, C. Optimizing environmental measures for landscape multifunctionality: Effectiveness, efficiency and recommendations for agri-environmental programs. J. Environ. Manag. 2015, 151, 243-257. [CrossRef] [PubMed]

23. Scolozzi, R.; Morri, E.; Santolini, R. Delphi-based change assessment in ecosystem service values to support strategic spatial planning in Italian landscapes. Ecol. Indic. 2012, 21, 134-144. [CrossRef]

24. Wende, W.; Huelsmann, W.; Marty, M.; Penn-Bressel, G.; Bobylev, N. Climate protection and compact urban structures in spatial planning and local construction plans in Germany. Land Use Policy 2010, 27, 864-868. [CrossRef]

25. Lin, J.Y.; Li, X. MFOZ planning of Dongguan based on spatial autocorrelation by using genetic algorithms. Geogr. Res. 2014, 33, 349-357. (In Chinese)

26. Fan, J. The scientific foundation of major function-oriented zoning in China. Acta Geogr. Sin. 2007, 62, 339-350. (In Chinese) [CrossRef] 
27. Liu, J.L.; Liu, Y.S.; Li, Y.R. Classification evaluation and spatial-temporal analysis of "production-living-ecological" spaces in China. Acta Geogr. Sin. 2017, 72, 1290-1304. (In Chinese)

28. Du, G.M.; Sun, X.B.; Wang, J.Y. Spatiotemporal patterns of multi-functionality of land use in northeast China. Prog. Geogr. 2016, 35, 232-244. (In Chinese)

29. Feng, W.; Dong, Y.X. Spatial differences and influencing factors of land use function in Guangzhou. Resour. Sci. 2015, 37, 2179-2192. (In Chinese)

30. Nian, P.H.; Cai, Y.M.; Xie, Y.Z.; Zhang, W.X.; Ma, S.F. Geographical space comprehensive function zoning in Hunan Province nased on niche theory. Resour. Sci. 2014, 36, 1958-1968. (In Chinese)

31. Ma, L.B.; Niu, S.W.; Shi, P.J.; Guo, X.D. The functional zoning of territorial space and the developmental pattern of future space-based on the framework of the major function oriented zoning. Econ. Geogr. 2015, 35, 68-77. (In Chinese)

32. Huang, J.C.; Lin, H.X.; Qi, X.X. A literature review on optimization of spatial development pattern based on ecological-production-living space. Prog. Geogr. 2017, 36, 378-391. (In Chinese)

33. Fan, Y.; Jin, X.; Gan, L.; Jessup, L.H.; Pijanowski, B.C.; Yang, X.; Xiang, X.; Zhou, Y. Spatial identification and dynamic analysis of land use functions reveals distinct zones of multiple functions in eastern China. Sci. Total Environ. 2018, 642, 33-44. [CrossRef] [PubMed]

34. Zhou, D.; Xu, J.C.; Lin, Z.L. Conflict or coordination? Assessing land use multi-functionalization using production-living-ecology analysis. Sci. Total Environ. 2016, 577, 136-147. [CrossRef] [PubMed]

35. Shen, Y.; Yan, J.M.; Chen, H. Land consolidation function unit demarcation based on optimization of production, living and ecology space in peri-urban areas. Trans. CSAE 2018, 34, 243-252. (In Chinese)

36. Liu, X.; Zhao, Y.X.; Feng, X.M.; Wu, A.B.; Li, R.H. Simulation and optimization of multi-objective land use pattern based on the CLUE-S model: A case study of the three northern counties of Langfang in Hebei Province. Geogr. Geo-Inf. Sci. 2018, 34, 92-98. (In Chinese)

37. Chang, Y.C.; Ko, T.T. An interactive dynamic multi-objective programming model to support better land use planning. Land Use Policy 2014, 36, 13-22. [CrossRef]

38. Asgari, N.; Farahani, R.Z.; Bajgan, H.R.; Sajadieh, M.S. Developing model-based software to optimise wheat storage and transportation: A real-world application. Appl. Soft Comput. 2013, 13, 1074-1084. [CrossRef]

39. Zhang, H.H.; Zeng, Y.N.; Jin, X.B.; Shu, B.R.; Zhou, Y.K.; Yang, X.H. Simulating multi-objective land use optimization allocation using Multi-agent system-A case study in Changsha, China. Ecol. Model. 2016, 320, 334-347. [CrossRef]

40. Gao, Q.Z.; Kang, M.Y.; Xu, H.M.; Jiang, Y.; Yang, J. Optimization of land use structure and spatial pattern for the semi-arid loess hilly-gully region in China. Catena 2010, 81, 196-202. [CrossRef]

41. Yang, X.; Zheng, X.Q.; Lv, L.N. A spatiotemporal model ofland use change based on ant colony optimization, Markov chain and cellular automata. Ecol. Model. 2012, 233, 11-19. [CrossRef]

42. Verburg, P.H.; Soepboer, W.; Veldkamp, A.; Limpiada, R.; Espaldon, V. Modeling the spatial dynamics of regional land use: The CLUE-S model. Environ. Manag. 2002, 30, 391-405. [CrossRef] [PubMed]

43. Jiang, W.G.; Deng, Y.; Tang, Z.H.; Lei, X.; Chen, Z. Modelling the potential impacts of urban ecosystem changes on carbon storage under different scenarios by linking the CLUE-S and the InVEST models. Ecol. Model. 2017, 345, 30-40. [CrossRef]

44. Zheng, F.Y.; Hu, Y.C. Assessing temporal-spatial land use simulation effects with CLUE-S and Markov-CA models in Beijing. Environ. Sci. Pollut. Res. 2018, 25, 32231-32245. [CrossRef] [PubMed]

45. Zhou, F.; Xu, Y.; Chen, Y.; Xu, C.Y.; Gao, Y.; Du, J. Hydrological response to urbanization at different spatio-temporal scales simulated by coupling of CLUE-S and the SWAT model in the Yangtze River Delta region. J. Hydrol. 2013, 485, 113-125. [CrossRef]

46. Wu, M.; Ren, X.Y.; Che, Y.; Yang, K. A Coupled SD and CLUE-S model for exploring the impact of land use change on ecosystem service value: A Case Study in Baoshan District, Shanghai, China. Environ. Manag. 2015, 56, 402-419. [CrossRef] [PubMed]

47. Kleeman, J.; Baysal, G.; Bulley, H.N.N.; Fürst, C. Assessing driving forces of land use and land cover changes by a mixed-method approach in northern-eastern Ghana, West Africa. J. Environ. Manag. 2017, 196, 411-442. [CrossRef]

48. Wang, Q.; Ren, Q.F.; Liu, J.F. Identification and apportionment of the drivers of land use change on a regional scale: Unbiased recursive partitioning-based stochastic model application. Agric. Ecosyst. Environ. 2016, 217, 99-110. [CrossRef] 
49. Mottet, A.; Ladet, S.; Coqué, N.; Gibon, A. Agricultural land-use change and its drivers in mountain landscapes: A case study in the Pyrenees. Agric. Ecosyst. Environ. 2006, 114, 296-310. [CrossRef]

50. Kolb, M.; Mas, J.F.; Galicia, L. Evaluating drivers of land-use change and transition potential models in a complex landscape in Southern Mexico. Int. J. Geogr. Inf. Sci. 2013, 27, 1804-1827. [CrossRef]

51. Yang, J.F.; Lei, K.; Khu, S.; Meng, W.; Qiao, F. Assessment of water environmental carrying capacity for sustainable development using a coupled system dynamics approach applied to the Tieling of the Liao River Basin, China. Environ. Earth Sci. 2015, 73, 5173-5183. [CrossRef]

52. Ye, W.; Xu, X.Y.; Wang, H.X.; Yang, H.C.; Yang, Z.W. Quantitative assessment of resources and environmental carrying capacity in the northwest temperate continental climate ecotope of China. Environ. Earth Sci. 2016, 75, 868. [CrossRef]

53. Cheng, J.Y.; Zhou, K.; Chen, D.; Fan, J. Evaluation and analysis of provincial differences in resources and environment carrying capacity in China. Chin. Geogr. Sci. 2016, 26, 539-549. [CrossRef]

54. Zhang, M.; Liu, Y.M.; Wu, J.; Wang, T.T. Index system of urban resource and environment carrying capacity based on ecological civilization. Environ. Impact Assess. Rev. 2018, 68, 90-97. [CrossRef]

55. Zhao, L.P.; Li, B.X.; Wang, Y.P.; He, K. Study on temporal and spatial coupling coordination of urbanization and water-soil resources of grain production. Econ. Geogr. 2016, 36, 145-152. (In Chinese)

56. Zhou, Q.G.; Zhang, X.Y.; Wang, Z.L. Land use ecological risk evaluation in three gorges reservoir area based on normal cloud model. Trans. CSAE 2014, 30, 289-297. (In Chinese)

57. Mao, X.Y.; Meng, J.J.; Xiang, Y.Y. Cellular automata-based modelfor developing land use ecological security patterns in semi-arid areas: A case study of Ordos, Inner Mongolia, China. Environ. Earth Sci. 2013, 70, 269-279. [CrossRef]

58. Grilli, A.R.; Schumchenia, E.J. Toward wind farm monitoring optimization: Assessment of ecological zones from marine landscapes using machine learning algorithms. Hydrobiologia 2015, 756, 117-137. [CrossRef]

59. Setälä, H.; Bardgett, R.D.; Birkhofer, K.; Brady, M.; Byrne, L.; de Ruiter, P.C.; de Vries, F.T.; Gardi, C.; Hedlund, K.; Hemerik, L.; et al. Urban and agricultural soils: Conflicts and trade-offs in the optimization of ecosystem services. Urban Ecosyst. 2014, 17, 239-253. [CrossRef]

60. Cui, H.J.; Guo, P.; Li, M.; Guo, S.S.; Zhang, F. A multi-risk assessment framework for agricultural land use optimization. Stoch. Environ. Res. Risk Assess. 2019, 33, 563-579. [CrossRef]

61. Mohammadi, M.; Nastaran, M.; Sahebgharani, A. Development, application, and comparison of hybrid meta-heuristics for urban land-use allocation optimization: Tabu search, genetic, GRASP, and simulated annealing algorithms. Environ. Urban Syst. 2016, 60, 23-36. [CrossRef]

62. Pirjo, P.S.; Lauri, J.; Heikki, L.; Jaana, S.; Eija, H.; Samantha, W.; Mika, K.; Eetu, P. Land use optimization tool for sustainable intensification of high-latitude agricultural systems. Land Use Policy 2019, 88, 1-10.

63. Lu, S.S.; Guan, X.L.; Zhou, M.; Wang, Y. Land resources allocation strategies in an urban area involving uncertainty: A case study of Suzhou, in the Yangtze River Delta of China. Environ. Manag. 2014, 53, 894-912. [CrossRef] [PubMed]

64. Nie, Y.; Avraamidou, S.; Xiao, X.; Pistikopoulos, E.; Li, J.; Zeng, Y.; Song, F.; Yu, J.; Zhu, M. A food-energy-water nexus approach for land use optimization. Sci. Total Environ. 2019, 659, 7-19. [CrossRef] [PubMed]

65. Ma, B.Y.; Huang, J.; Li, S.C. Optimal allocation of land use types in the Beijing-Tianjin-Hebei urban agglomeration based on ecological and economic benefits trade-offs. Prog. Geogr. 2019, 38, 26-37. (In Chinese)

66. Cobuloglu, H.; Büyüktahtakin, I. Food vs. biofuel: An optimization approach to the spatio-temporal analysis of land-use competition and environmental impacts. Appl. Energy 2015, 140, 418-434. [CrossRef]

67. Xu, E.Q.; Zhang, H.Q.; Li, M.X. Mining spatial information to investigate the evolution of karst rocky desertification and its human driving forces in Changshun, China. Sci. Total Environ. 2013, 458-460, 419-426. [CrossRef]

68. Vakanjac, V.R.; Stevanović, Z.; Stevanović, A.M.; Vakanjac, B.; Marina, C.I. An example of karst catchment delineation for prioritizing the protection of an intact natural area. Environ. Earth Sci. 2015, 74, 7643-7653. [CrossRef]

69. Petrič, M.; Kogovšek, J. Identifying the characteristics of groundwater flow in the Classical Karst area (Slovenia/Italy) by means of tracer tests. Environ Earth Sci. 2016, 75, 1446. [CrossRef]

70. Šturm, T.; Podobnikar, T. A probability model for long-term forest fire occurrence in the Karst forest management area of Slovenia. Int. J. Wildl. Fire 2017, 26, 399-412. [CrossRef] 
71. Achurra, A.; Rodriguez, P. Biodiversity of groundwater oligochaetes from a karst unit in northern Iberian Peninsula: Ranking subterranean sites for conservation management. Hydrobiologia 2008, 605, 159-171. [CrossRef]

72. Eckhardt, K.; Breuer, L.; Frede, H.G. Parameter uncertainty and the significance of simulated land use change effects. J. Hydrol. 2003, 273, 164-176. [CrossRef]

73. Verburg, P.H.; Tabeau, A.; Hatna, E. Assessing spatial uncertainties of land allocation using a scenario approach and sensitivity analysis: A study for land use in Europe. J. Environ. Manag. 2012, 127, S132-S144. [CrossRef] [PubMed]

74. Prestele, R.; Alexander, P.; Rounsevell, M.; Arneth, A.; Calvin, K.; Doelman, J.; Eitelberg, D.A.; Engström, K.; Fujimori, S.; Hasegawa, T.; et al. Hotspots of uncertainty in land use and land cover change projections: A global scale model comparison. Glob. Chang. Biol. 2016, 22, 3967-3983. [CrossRef]

75. Cheng, H.; Xu, Q.; Guo, Y.Q. Temporal and spatial evolution of the coupling Coordinated development between tourism resources development and ecological environment in China. Econ. Geogr. 2019, 39, $233-240$. (In Chinese)

76. Wang, Q.S.; Yuan, X.L.; Cheng, X.X.; Mu, R.M.; Zuo, J. Coordinated development of energy, economy and environment subsystems-A case study. Ecol. Indic. 2014, 46, 514-523. [CrossRef]

77. Hao, R.F.; Yu, D.Y. Optimization schemes for grassland ecosystem services under climate change. Ecol. Indic. 2018, 85, 1158-1169. [CrossRef]

78. Jiang, S.J.; Shen, L.Y.; Zhou, L. Empirical study on the contribution of infrastructure to the coordinated development between urban and rural areas: Case study on country road projects. Procedia Environ. Sci. 2011, 11, 1113-1118.

79. Konur, D.; Schaefer, B. Economic and environmental comparison of grouping strategies in coordinated multi-item inventory systems. J. Oper. Res. Soc. 2016, 67, 421-436. [CrossRef]

80. Zhang, H.M.; Zhu, Z.S.; Fan, Y.J. The impact of environmental regulation on the coordinated development of environment and economy in China. Nat. Hazards 2018, 91, 473-487. [CrossRef]

81. Zhao, X.Q.; Li, S.N.; Tan, K.; Miao, P.P.; Pu, J.W.; Lu, F.F.; Wang, Q. Land use optimization of plateau lake basin based on town-agriculture-ecological spatial coordination. Trans. CSAE 2019, 35, 296-307. (In Chinese)

82. Bennett, E.M.; Peterson, G.D.; Gordon, L.J. Understanding relationships among multiple ecosystem services. Ecol. Lett. 2009, 12, 1394-1404. [CrossRef] [PubMed]

83. Baró, F.; Palomo, I.; Zulian, G.; Vizcaino, P.; Haase, D.; Gómez, B.E. Mapping ecosystem service capacity, flow and demand for landscape and urban planning: A case study in the Barcelona metropolitan region. Land Use Policy 2016, 57, 405-417. [CrossRef]

84. Long, H.L. Land use transition and land management. Geogr. Res. 2015, 35, 1607-1618. (In Chinese)

85. Shen, Z.Y.; Qiu, J.L.; Hong, Q.; Chen, L. Simulation of spatial and temporal distributions of non-point source pollution load in the Three Gorges Reservoir Region. Sci. Total Environ. 2014, 493, 138-146. [CrossRef] [PubMed]

86. Yue, Y.M.; Zhang, B.; Wang, K.-L.; Liu, B.; Li, R.; Jiao, Q.; Yang, Q.; Zhang, M.-Y. Spectral indices for estimating ecological indicators of karst rocky desertification. Int. J. Remote Sens. 2010, 31, 2115-2122. [CrossRef]

87. Stott, I.; Soga, M.; Inger, R.; Gaston, K.J. Land sparing is crucial for urban ecosystem services. Front. Ecol. Environ. 2015, 13, 387-393. [CrossRef]

(C) 2019 by the authors. Licensee MDPI, Basel, Switzerland. This article is an open access article distributed under the terms and conditions of the Creative Commons Attribution (CC BY) license (http://creativecommons.org/licenses/by/4.0/). 